\title{
Histone-Lysine N-Methyltransferase SETDB1
}

National Cancer Institute

\section{Source}

National Cancer Institute. Histone-Lysine N-Methyltransferase SETDB1. NCI Thesaurus.

Code C29940.

Histone-lysine N-methyltransferase SET DB1 (1291 aa, 143 kDa) is encoded by the human SETDB1 gene. This protein is involved in histone methylation. 